\title{
O combate ao terrorismo e a expansão do Direito Penal
}

\author{
The counter terrorism and the expansion of the Criminal Law
}

\author{
ANDRÉ LUÍS CALLEGARI ${ }^{1}$ \\ Doutor em Direito pela Universidad Autónoma de Madrid \\ RAUL MARQUES LINHARES ${ }^{2}$ \\ Bacharelando em Ciências Jurídicas e Sociais pela Universidade do Vale do Rio dos Sinos - UNISINOS
}

\begin{abstract}
RESUMO: Com as constantes e instantâneas modificações da sociedade moderna, por vezes qualificada como "sociedade do risco", verifica-se uma gradual transformação dos desejos sociais e de sua expectativa em relação ao Direito Penal. Nesse cenário, constata-se um fenômeno de expansão do direito penal, na busca por respostas aos desejos da sociedade em geral. Considerando algumas manifestações dessa expansão do Direito Penal, o fenômeno terrorista passa a adotar o foco das atenções dos discursos repressivos. Então, com a intenção de compreender melhor esse processo expansivo do Direito Penal e o discurso de combate ao terrorismo, procurar-se-á estudar ambos os assuntos.
\end{abstract}

Palavras-chaves: Direito Penal. Expansão. Terrorismo.

ABSTRACT: With the constant and instantaneous changes of modern society, sometimes described as "risk society", there is a gradual transformation of social wishes and their expectations in relation to criminal law. In this scenery, there is a tendency for expansion of criminal law, in the search for answers to wishes of society in general. Considering some manifestations from criminal law expansion, the terrorist phenomenon will adopt the spotlight of the repressive discourses. So, with the intention to understand better this expansive process of criminal law and discourse to counter terrorism, will be search study that two subjects.

Keywords: Criminal law. Expansion. Terrorism.

\section{INTRODUÇÃO}

A sociedade moderna tem experimentado rápidas mudanças, de diversas ordens, nos últimos anos. Novas formas de relação são instituídas, novos acontecimentos presenciados, entre outras inovações. Atualmente, pode-se identificar a configuração de uma sociedade tomada pela complexidade, marcada pela relativização de fronteiras e demais formas de divisão, proporcionando uma intensa comunicabilidade $\mathrm{e}$ choques culturais.

Nesse momento atual, destaca-se o avanço tecnológico, que permitiu a "aproximação" dos distantes. Como consequência, produz-se uma realidade tomada pela instantaneidade e pelo excesso de informações, além dos riscos criados por esse desenvolvimento. Nesse sentido, refere Ana Isabel Pérez Cepeda que, em parte, é devido ao avanço tecnológico o aumento de criminalizações presenciado atualmente, pois traz consigo novos riscos à sociedade, característica da sociedade pós-industrial ${ }^{3}$.
Em razão do aumento notável de informações e dos novos riscos (além de outros fatores), novas necessidades surgem na sociedade, como, por exemplo, a de aumento da segurança.

Essa demanda por segurança se faz presente de forma ainda mais marcante em razão de novas manifestações sociais, especialmente de uma: o terrorismo.

O terrorismo foi alçado à posição de maior ameaça da tranquilidade geral ${ }^{4}$. Não se refuta, aqui, a gravidade do fenômeno terrorista. Pretende-se apresentar uma crítica ao tratamento que vem sendo oferecido a esse fenômeno, principalmente no âmbito de um Direito Penal expansionista, como a seguir será abordado.

\section{LINHAS GERAIS SOBRE A EXPANSÃO DO DIREITO PENAL}

O notável desenvolvimento experimentado pela humanidade nos últimos tempos trouxe realidades novas. $\mathrm{Na}$ atual sociedade, tomada pelo avanço 
tecnológico e pela instantaneidade (seja de informações, de relação, de inovações, de sentimentos etc.), algumas realidades novas se apresentaram e, com elas, novas necessidades sociais se impõem.

$\mathrm{O}$ antigo sentimento de controle humano sobre os acontecimentos mundanos ou a mera sensação de segurança no convívio social, nessa sociedade, cederam espaço a sensações de impotência e medo. Isso ocorre por diversos fatores, boa parte fruto do "desenvolvimento", desenhando-se no contexto global uma forma de vida cada vez mais aberta a riscos invisíveis (como, por exemplo, a ameaça nuclear).

Esse cenário levou Zygmunt Bauman a dizer que tudo é "líquido" 5 no mundo moderno. Nesse sentido, Bauman discorre sobre a denominada "síndrome do Titanic", porquanto as pessoas se encontram imersas na sensação de que, a qualquer momento, serão tomadas por uma catástrofe imprevisível que porá abaixo a estrutura de convívio social, instaurando uma ordem de pânico. Apesar da incontável diversidade de riscos existentes, o autor reserva uma posição especial ao "iceberg terrorista" , que considera ser a ameaça mais temida atualmente.

O sentimento de insegurança se dissemina com facilidade na atual sociedade e, com isso, cada vez mais exigências por políticas de combate à criminalidade são direcionadas ao Estado.

A causa dessa crescente incidência do sentimento de medo se deve a diversos fatores, dentre os quais parcela considerável se deve aos meios de comunicação de massa. Ou seja, a mídia tem grande responsabilidade pelo sentimento de insegurança social, inclusive por ver nesse mercado do noticiário populista um excelente mercado ${ }^{8}$. Em razão disso, tem-se que o "estado anímico da massa" é um fator preponderante de estímulo à produção midiática, que possui por ambição maior a venda de notícias ${ }^{9}$ e, infelizmente, o noticiário violento tem representado uma aceitabilidade social notável.

Devido à instantaneidade da informação alcançada pela evolução dos sistemas comunicacionais, fatos que antes sequer chegavam ao conhecimento da maioria das pessoas e se restringiam ao conhecimento em uma pequena parcela populacional, hoje são difundidos pelo mundo inteiro, em uma velocidade nunca antes vista.

Ao final desse processo informativo, o que se verifica é uma relação direta entre a quantidade de informação a respeito de episódios de violência e o sentimento de insegurança, o primeiro incidindo sobre o segundo ${ }^{10}$.

Considerando que a quantidade de notícias a respeito de ações violentas não mantém qualquer relação necessária com o número de ações realmente ocorridas, a maior ou menor difusão de informações a isso relacionadas passa a ter a capacidade de desenvolver sentimentos de (in)segurança desconectados da realidade. Nesse sentido, Jacques A. Wainberg refere que "[...] o papel da mídia em carregar a mente com imagens de um mundo hostil - mais hostil do que é - foi confirmado noutro estudo que revelou ser a sensação de medo do público resultado mais do noticiário televisivo do que propriamente dos indicadores de criminalidade pública"11. Tem-se, pois, que, para a massa, a verdade é o que se presencia; não in locu ou diretamente, mas cotidianamente em noticiários (nem sempre confiáveis) ${ }^{12}$.

Consequentemente, a mídia passa a ter a capacidade de manusear os sentimentos sociais, tornandose capacitada, por exemplo, para criar mesmo nas camadas mais humildes da população o temor de serem vitimadas pelo cometimento de crimes patrimoniais, como o roubo e a extorsão mediante sequestro ${ }^{13}$.

Assim, o que se desenvolve é um poder midiático na determinação da forma pela qual a sociedade enxergará os "problemas sociais", tudo de acordo com uma lógica mercadológica na qual a busca pela audiência é o que dita as regras ${ }^{14}$.

Diante do clamor por segurança e da necessidade de se oferecer uma resposta à sociedade (somados ao descrédito atual do Legislativo nacional), o Direito Penal é acionado para atuar com frequência. Lamentavelmente, essa atuação se apresenta de forma impensada ou, se pensada, de forma incompatível com a função classicamente outorgada ao Direito Penal.

Para a maior parte da sociedade, o Direito Penal é considerado a solução necessária ao tratamento do fenômeno da violência, assim se iniciando a motivação para uma inflação desse ramo do Direito, com a criação de novos tipos penais e o agravamento dos já existentes. Porém, é fácil perceber que esse movimento expansionista do Direito Penal não resulta em efeitos benéficos como se costuma imaginar, verificando-se um uso meramente simbólico.

Tem-se o Direito Penal simbólico quando “[...] determinados agentes políticos tão só perseguem o objetivo de dar a 'impressão tranquilizadora de um legislador atento e decidido' [...]"15. Ou seja, instaurase uma utilização estritamente para fins políticos do Direito Penal, deixando-se seus efeitos práticos e legítimos em um segundo plano. Por isso se deve identificar o Direito Penal simbólico não a uma espécie específica de infrações, mas à importância política conferida pelo legislador às normas penais ${ }^{16}$.

Nessa realidade, a intervenção penal destina-se predominantemente a controlar os sentimentos sociais relativos à delinquência ${ }^{17}$. Passa ele a adotar a imagem de solução fácil aos problemas sociais, conquanto 
seja mera uma "imagem de solução"18. Desse modo, como refere Zygmunt Bauman, "Os perigos que mais tememos são imediatos: compreensivelmente, também desejamos que os remédios o sejam - 'doses rápidas', oferecendo alívio imediato, como analgésicos prontos para o consumo"19.

A facilidade na aprovação de novas leis penais e o agravamento das já existentes reflete, em sua contraface, a dificuldade de se revogar expressamente ou amenizar as leis penais vigentes. Isso resulta da inexistência (ou existência insignificante) de oposição à política repressivista. A oposição à ideologia de repressão ao crime, em nosso meio político, é majoritariamente indesejável, considerando-se os negativos efeitos provavelmente ocasionados pelo estigma da defesa do "lobby do crime" 20 .

Em razão do domínio dessa expansão do Direito Penal, inúmeros fatores se manifestam no ordenamento penal e processual penal que, em um tempo anterior, eram desconhecidos ou combatidos. Um exemplo desses fatores é a flexibilização de garantias processuais e de regras de imputação penal, além da flexibilização dos próprios princípios fundantes do Direito Penal, como o princípio da legalidade.

Considerando a tendência punitivista, a facilidade de aprovação ou agravamento de leis penais, o exercício do processo legislativo fundado em meros fins eleitoreiros e o descrédito da opinião dos especialistas na discussão legislativa (outra das manifestações da expansão do Direito Penal ${ }^{21}$, a legislação penal e processual penal acaba por sofrer reformas nem sempre adequadas à boa técnica e, desse modo, a precisão e clareza da lei são, por vezes, sacrificadas em razão de redações abstratas, dúbias, imprecisas.

$\mathrm{Na}$ lição de Cesare Beccaria, deve-se ter por grande mal a instituição de leis escritas em linguagem desconhecida ou obscura ao conhecimento geral ${ }^{22}$. Isso se fundamenta na própria finalidade de segurança do princípio da legalidade. Essa segurança legal guiadora do comportamento humano, no magistério de Douglas Husak, encontra-se debilitada em razão do que denominou de "sobrecriminalização" (excesso da penalização de condutas) ${ }^{23}$.

Dessa forma, a corrente utilização legislativa de tipos penais abertos ou imprecisos se consubstancia em violação ao princípio da legalidade, especialmente em sua dimensão direcionada ao Poder Legislativo, ao determinar o respeito à exigência de clareza na redação dos tipos penais ${ }^{24}$.

Ao encontro do que até aqui foi exposto, Ana Isabel Pérez Cepeda sintetiza as principais manifestações do expansionismo penal, como se vê:
Con carácter general, se puede afirmar que el fenómeno expansivo, como se decía al principio, no sólo se ha traducido en un incremento continuado de comportamientos que se elevan a la categoría de delito, sino que ha dado paso a un nuevo modelo de política criminal que parece contradecir los principios programáticos que deben orientar la actividad legislativa en el campo penal. Así, unido a la flexibilidad de los criterios dogmáticos de imputación (por ejemplo, los relativos a la relación de causalidad, a la imputación objetiva de la conducta y el resultado, a la imputación subjetiva o la relación de autoría), existe una flexibilización de las garantías político-criminales materiales e procesal (por ejemplo, el principio de legalidad penal y procesal, la progresiva importancia de los acuerdos entre las partes en el proceso y la disminución de las formalidades del mismo, el principio de taxatividad en la elaboración de los tipos penales, el principio de irretroactividad de las disposiciones perjudiciales para el reo, el principio de prohibición de analogía in malam partem o el principio de culpabilidad $)^{25}$.

No seio dessa nova realidade, uma doutrina em especial tem recebido a maior parte das atenções. Tratase da teoria do Direito Penal do inimigo, desenvolvida por Günther Jakobs. Esse autor se fundamenta, sobretudo, nos doutrinadores contratualistas (Rousseau, Fichte, Hobbes e Kant) para instituir a bipartição do ordenamento penal, configurando um Direito Penal do cidadão, aplicável às pessoas em geral e respeitoso a todos os postulados legais instituídos, e um Direito Penal do inimigo, atuante no combate às pessoas que se afastam dos regramentos sociais.

A base dessa forma de tratamento do delinquente inimigo se encontra no fato de que ele não proporciona uma garantia cognitiva mínima de segurança ou de respeito ao direito, porquanto se posta de maneira afastada do ordenamento jurídico. Nesse sentido, Jakobs aponta, por exemplo, o sujeito que opta por integrar uma organização terrorista ${ }^{26}$.

Conforme leciona Enrique Bacigalupo, Jakobs defende o Direito Penal do inimigo como "[...] una tendencia del derecho actual que se propone 'luchar' contra el delito operando sobre el delincuente y que se justifica a sí misma por la decisión de los autores del delito de autoexcluirse de la comunidad jurídica"27.

Desse modo, se mantém instituído o Direito Penal regular, direcionado aos cidadãos que incidam nas proibições previstas, em respeito aos direitos e garantias assegurados pelo ordenamento jurídico. Quando, contudo, se estiver a tratar de um ato de alta traição, considerado por Jakobs uma rebelião contra a instituição do Estado, o sujeito não mais seria punido 
de acordo com os regramentos legais, mas como um mero inimigo a ser combatido, sujeito à coação física desmedida $^{28}$. Classifica-se o inimigo, nessa doutrina, como um ente perigoso ${ }^{29}$ a ser combatido, afastando-o do regramento convencional.

$\mathrm{Na}$ síntese de Francesco Viganò, no tocante às características do Direito Penal do inimigo, pode-se dizer que se manifesta pelas seguintes características:

[...] a) l'accentuato arretramento della tutela penale ad atti meramente preparatori, b) altissimi livelli sanzionatori (senza alcuna riduzione della pena proporzionale all'arretramento della tutela rispetto all'offensa al bene finale) e c) una corrispondente riduzione, sul piano processuale, delle garanzie difensive nei procedimento aventi ad oggeto 'nemici', e non comuni delinquenti ${ }^{30}$. (Grifo do autor)

Percebe-se, aqui, que as indicadas características do Direito Penal do inimigo já se manifestam, em maior ou menor intensidade, no ordenamento jurídico vigente, como apontado no estudo da expansão penal. Há que se destacar, contudo, o centro de atenção dessa forma de atuação penal, qual seja o combate ao terrorismo. $\mathrm{Na}$ lição de Manuel Cancio Meliá, no ordenamento jurídico espanhol, o Direito antiterrorista apresenta acentuadas características identificadoras do Direito Penal do inimigo ${ }^{31}$. Tem-se que, internacionalmente, o Direito Penal do inimigo tende a ser constantemente evocado quando se discute o fenômeno terrorista.

Deve-se, todavia, questionar a aplicação dessa doutrina (seja nos casos de terrorismo, seja em outros casos) em um sistema jurídico penal que, como o nosso, se fundamenta em uma diversidade de postulados democráticos superiores, especialmente pela incompatibilidade do Direito Penal do inimigo com o Direito em si. Nesse sentido, Manuel Cancio Meliá refere que "Direito Penal do inimigo" é, em verdade, uma contradição de termos ${ }^{32}$.

Por isso, a problemática relativa ao tratamento conferido atualmente ao terrorismo é tomada de imensa importância. Por meio dela, pode-se traçar uma diretriz (mesmo que inicial) a ser seguida no que se refere ao combate ao terrorismo, possibilitando, ao final, seguir um caminho fundado, seja optando-se pela aplicação do Direito Penal, seja pela atuação de um tratamento bélico.

\section{TRATAMENTO PENAL DO TERRORISMO VS TRATAMENTO BELIGERANTE}

Conforme indica Pino Arlacchi, ainda inexiste uma definição universalmente aceita de terrorismo ${ }^{33}$.
Alguns autores, a exemplo de Mário Capita Remezal ${ }^{34}$ e Manuel Cancio Meliáa ${ }^{35}$, se direcionam a conceitos eminentemente jurídico-penais de terrorismo. Todavia, alguns elementos caracterizadores desse fenômeno são aventados doutrinariamente.

Para facilitar a identificação jurídica do terrorismo, parte da doutrina se utiliza de um método conceitual bipartido, descrevendo um elemento estrutural (forma de configuração e atuação) e um elemento teleológico

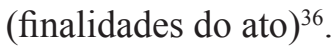

Nesse sentido é a lição de Arroyo Zapatero, para quem "[...] puede ensayarse una definición jurídica del problema 'terrorismo' conjugando dos elementos. De una parte, los medios empleados y los resultados producidos por los autores de las prácticas terroristas $\mathrm{y}$, de otra, la finalidad que se persigue" 37 .

Dentre os elementos que compõem o terrorismo, deve-se destacar aquele que majoritariamente é mencionado e que compõe o próprio nome desse fenômeno social: o discurso do terror. Nesse sentido, indica-se o "[...] objetivo de crear una atmósfera de terror $[\ldots] " 38$ como o elemento principal de identidade do terrorismo. Esse mesmo entendimento é partilhado por Manuel Becerra Ramírez ${ }^{39}$.

O próprio termo terrorismo, em sua acepção comum, significa "[...] um estado psíquico de grande medo ou pavor" 40 . Constitui essa, portanto, a arma suprema do terrorismo ${ }^{41}$ e a sua distinta natureza comunicacional e indiscriminada.

Desse modo, o terrorismo reflete a necessidade de se outorgar ao ato uma maior publicidade para o alcance de seus objetivos ${ }^{42}$, externando-se essa publicidade pela disseminação do sentimento de terror, próprio desse fenômeno. Por isso o dizer de Jacques A. Wainberg, para quem "[...] esse fenômeno social e político do terror não ocorreria se não fosse também, e em essência, um fenômeno comunicacional"43.

Conquanto sejam alguns elementos traçados para conceituação do terrorismo, como o objetivo de instauração de um ambiente de terror, mantém-se em aberto sua conceituação, pois ainda não alcançado uma definição uniforme (existindo, em diversos países, conceitos desenvolvidos estritamente para fins penais).

Deixando de lado o questionamento sobre sua conceituação, deve-se discutir sobre a forma de combate a ser direcionado a esse fenômeno.

Quando se trabalha o combate ao terrorismo, é inevitável se perguntar, assim como fez Francesco Viganò, se é possível deter um terrorista com um "Código Penal de paz"44.

Como é próprio de uma sociedade tomada pelos efeitos da expansão do Direito Penal, que faz produzir seus efeitos especialmente nas atividades delituosas 
que mais alteram o ânimo social em razão de sua gravidade, vivenciamos uma tendência ao agravamento da resposta legal aos crimes em geral. Conforme a lição de Manuel Cancio Meliá, a atuação do Direito Penal em caráter preventivo possui uma complexidade muito maior do que supõe o discurso político-criminal dominante, segundo o qual se defende, erroneamente, "[...] una correlación directa entre mayores niveles de 'dureza' del ordenamiento penal y mayores niveles de eficacia preventiva" ${ }^{45}$. No combate ao terrorismo, esse tipo de manifestação se faz presente de forma evidente.

Todavia, não existe qualquer evidência de que um tratamento penal mais rigoroso representará maior eficácia preventiva. Isso não quer significar que se deva retirar a atuação do Direito Penal no combate ao terrorismo, mas que se deva reconhecer o caráter extremamente mais amplo do fenômeno terrorista, como estratégia comunicacional de poder, que deve ser analisado sob um enfoque predominantemente social ${ }^{46}$. Essa compreensão se faz necessária para que se possa oferecer a medida correta para tratamento do terrorismo, porquanto, nas palavras de Douglas Husak, "Si esperamos reducir estas tendencias perniciosas debemos tratar de entender las fuerzas que han ayudado a crearlas y sostenerlas" 47 .

Deve-se ter claro, ainda, que determinadas formas de repressão ao terrorismo podem se apresentar contraproducente devido à sua gravidade ${ }^{48}$. Isso decorre do fato de que o terrorismo é, efetivamente, beneficiado com a política de guerra ao próprio terrorismo. Considerando que seu objetivo é a difusão do terror para alcance de um objetivo político final, o terrorismo tem na ideologia agressiva de seu combate um fator aliado à criação de uma atmosfera de pânico. Ao ser considerado um inimigo do Estado e da sociedade, merecedor de medidas tão drásticas quanto aquelas próprias de uma guerra declarada (perceptível na política de combate ao terrorismo dos Estados Unidos da América), o terrorismo adquire status de ente dotado de um poder que na verdade não tem e o sentimento de medo se difunde com maior facilidade nas pessoas, que se veem sujeitas a esse poder.

Luigi Ferrajoli elenca os equívocos cometidos por alguns países no combate ao terrorismo. Entre eles, temos a elevação do fenômeno terrorista a uma questão de guerra, ao invés de um problema passível de uma ação policial coordenada internacionalmente; a consideração do agente terrorista como combatente beligerante (postura própria do Direito Penal do inimigo, de Gunther Jakobs) e não como criminoso; e a representação do ato terrorista como uma agressão militar, não mais como uma atividade criminosa típica do tratamento do Direito Penal. Segue o autor referindo que tais posturas apenas servem de fatores de legitimação do terrorismo, que se vê elevado à categoria de potência inimiga, além de representarem, mais do que a renúncia da política e da lei, a renúncia da razão ${ }^{49}$.

Admite Luigi Ferrajoli que, sozinho, o Direito Penal não é suficiente ao combate de uma forma de criminalidade tão complexa como é o terrorismo, sendo necessárias medidas de política internacional bem coordenadas ${ }^{50}$. Todavia, admite que não se deve negar ao terrorismo seu caráter de atividade criminosa e, por isso, merecedora do tratamento do Direito Penal, afastando-se a aplicação de medidas próprias de guerra, resposta contrária à lógica do Direito. Como refere o autor, no combate ao terrorismo "[...] è proprio la risposta asimmetrica e garantista del diritto penale, in alternativa a quella irrazionale e simmetrica della guerra, che vale a depotenziarlo politicamente e a isolarlo socialmente come fenomeno, appunto, criminale" ${ }^{51}$.

Não só o Direito Penal isolado se apresenta como medida ineficaz na prevenção ao terrorismo, como deve ser manuseado com cautela e com um profundo estudo crítico de suas implicações para que sejam evitados resultados gravosos. Essa capacidade de efeito contrário merece atenção especial, pois "[...] ni debe darse por supuesto que el Derecho penal antiterrorista pueda prevenir eficazmente las infracciones que reprime, ni deben olvidarse los costes de contaminación que una determinada orientación de su regulación puede ocasionar" 52 (grifo do autor).

$\mathrm{Ou}$ seja, em um primeiro momento, deve-se atentar para a natureza de extrema complexidade do fenômeno terrorista, que, assim como os demais fatos criminosos, mas talvez mais do que eles, não se consubstancia unicamente em uma questão penal e, dessa forma, resolúvel pela atuação do Direito Penal isolado. A capacidade do Direito Penal na prevenção de atos terroristas é (quase) nula, se chamado a agir como única medida.

Sob um segundo aspecto, deve-se atentar para a tendência da legislação anteterrorista em contaminar a legislação ordinária. É ilusória a imagem de que as alterações e criações legislativas direcionadas ao combate do terrorismo (que, normalmente, se manifestam por medidas drásticas, de gravidade consideravelmente elevada) se limitarão, a curto e longo prazo, aos atos de terrorismo. O que se verifica é a expansão dessa legislação, que, após passar por um "período de testes" na disciplina do terrorismo, acaba por ser adotada como medida aplicável aos demais crimes. Esse é o resultado verificável em grande parte das "leis de exceção" que, com o tempo, tendem a 
perder o caráter de exceção para se tornarem comuns. Veja-se, a título ilustrativo, a constante expansão do rol de crimes considerados hediondos, cada vez mais amplo e cada vez menos excepcional.

Ademais, as possibilidades de prevenção e persecução penal de agentes terroristas se mostram ainda mais enfraquecidas diante das características com as quais vem se apresentando alguns grupos: são, muitas vezes, suicidas, vinculados a religiões fundamentalistas, organizados em pequenos grupos autônomos, mas com conexões internacionais ${ }^{53}$. Nessa forma de organização, não se manifesta propriamente uma estrutura hierárquica, mas integrantes em situação de igualdade, que compõem grupos independentes, formando uma grande rede terrorista internacional.

Pelo acima exposto, vê-se que a adoção de medidas de gravidade excessiva sob o pretexto da luta contra o terrorismo seria, precisamente, mais uma forma de afirmação do simbolismo que assola o Direito Penal. Representaria essa política de combate ao terrorismo uma vitória conquistada pelo fenômeno terrorista. Todavia, simbolicamente, aos olhos da sociedade e do Estado, seriam vistas como mais uma (possível) arma na luta desesperada contra o terrorismo.

No entendimento de Mariona Llobet Anglí, medidas extraordinárias de combate a "inimigos" apenas são legítimas quando um Estado se encontra em situação de guerra - respeitados os limites do direito de guerra. Contra o terrorismo, contudo, apenas se devem aplicar as medidas de Direito Penal comum, com os limites impostos e típicos de um Estado democrático de direito. Isso decorre, dentre outros, do fato de que o terrorismo se configura em uma atividade ofensiva à vida, à integridade física, à liberdade das pessoas, dentre outros bens jurídicos, que também são atingidos por outras formas de crimes, os quais recebem o tratamento do Direito Penal, com respeito a todas as garantias constitucionais ${ }^{54}$.

Ainda, referindo-se a essa dicotomia entre escassez e excesso de violência no combate ao terrorismo, conforme reflexão de Fernando Reinares, citado por Manuel Cancio Meliá, a diferença entre as perspectivas políticas e jurídicas do fenômeno terrorista

[...] genera[n] no pocas tensiones que afectan al conjunto de una política gubernamental antiterrorista susceptible así de oscilar, de acuerdo con la coyuntura, entre el defecto y el exceso. Entre, por una parte, cierta tendencia a trivializar el terrorismo, reduciéndolo al orden de lo meramente criminal, negando o minimizando así su vinculación a situaciones de conflictividad política y rechazando cualquier tratamiento singularizado del fenómeno que se distancie de los supuestos legales ordinarios.
Por otra, actitudes inclinadas a exagerar las dimensiones del accionar terrorista y proclives a justificar un uso desproporcionado de la fuerza estatal en el control de dicha violencia ${ }^{55}$.

Deve-se primar, portanto, na tentativa de combate ao terrorismo, pela aplicação do Direito Penal, aliado a estratégias de investigação voltadas a identificação do grupo terrorista e neutralização de seu exercício. Ao inverso, é necessário evitar o tratamento do terrorismo como se ato de guerra fosse, assim se afastando o apelo à atuação de exércitos estatais e respostas violentas em demasia, que apenas alimentam ainda mais o terrorismo, porquanto o torna mais evidente, colaborando com a disseminação do sentimento de terror e alimentando uma possível vontade de vingança do grupo criminoso ${ }^{56}$.

\section{CONCLUSÃO}

Pelo exposto, torna-se clara a existência de um movimento expansivo do Direito Penal, acompanhado pela tendência evidente de defesa de políticas repressivistas no tocante ao tratamento penal dos fatos criminosos.

Essa ideologia se faz exaltada quando se trata do combate ao terrorismo e, com ela, se produz grande insegurança social, fruto das próprias manifestações do expansionismo penal, com as flexibilizações de garantias. No dizer de Zygmunt Bauman, a existência de alguns criminosos, hoje, é o suficiente para classificar multidões de inocentes como "suspeitos habituais" 57.

Passamos, assim, a um "novo modelo" de Direito Penal, distinto daquele conhecido por clássico. No tocante ao combate ao terrorismo, tem-se apostado, por vezes, na divisão defendida por Jakobs, não mais se considerando o terrorista como sujeito de direitos. Nesse caso, costuma se manifestar a aplicação de medidas próprias de guerra no combate ao fenômeno terrorista, descaracterizando-se completamente o Direito Penal e, em algumas ocasiões, qualquer forma de Direito. Ademais, não há demonstração de que essas medidas realmente surtem efeitos práticos positivos no combate ao terrorismo, também se manifestando na legislação antiterrorismo o simbolismo penal. A esse respeito é o dizer de Pérez Cepeda, para quem "Estas leyes excepcionales contienen un buen número de normas meramente simbólicas, de eficacia sólo aparente. Son más una respuesta política al terrorismo que una racional medida de eficacia penal" ${ }^{58}$.

Apesar dessa tendência ao agravamento das medidas de combate ao terrorismo, ainda se fazem presentes balizas constitucionais à aplicação de qual- 
quer medida contrária ao terrorismo. Ademais, parece ser de extrema dificuldade conter a influência de uma legislação especial nas demais legislações. Por isso, tamanhas flexibilizações de garantias possivelmente impostas ao tratamento legal de fatos criminosos isolados representariam uma ameaça a todas as demais garantias legais.

Há que se ter, assim, cautela no manuseio do Direito Penal nos dias atuais, especialmente em casos especiais como é o do terrorismo, matéria na qual o Direito já se aplica, hoje, de forma transformada. Conforme referido por Francesco Viganò, no tocante à sua atuação nos casos de terrorismo, o Direito Penal atual já é algo diverso do Direito Penal "clássico", modelando-se em torno de um paradigma bélico antes desconhecido ${ }^{59}$.

\section{REFERÊNCIAS}

ARLACCHI, Pino. Il mito del terrorismo. Revista de Estudos Criminais, São Paulo, ano 10, n. 45, p. 9-27, abr./jun. 2012.

BACIGALUPO, Enrique. Derecho penal y el Estado de Derecho. Chile: Editorial Juridica de Chile, 2005.

BAUMAN, Zygmunt. Medo líquido. Tradução de Carlos Alberto Medeiros. Rio de Janeiro: Zahar, 2008.

BECCARIA, Cesare. Dos delitos e das penas. Tradução Neury Carvalho Lima. São Paulo: Hunter Books, 2012.

BECERRA RAMÍREZ, Manuel. El 11 de septiembre y el derecho internacional. In: VALDÉS UGALDE, José Luis; VALADÉS, Diego (Org.). Globalidad y conflicto: Estados Unidos y la crisis de septiembre. México: Instituto de Investigaciones Jurídicas, 2002. p. $257-270$

CALLEGARI, André Luís. Teoria geral do delito e da imputação objetiva. 3. ed. São Paulo: Atlas, 2014.

CALLEGARI, André Luis; WERMUTH, Maiquel Ângelo Dezordi. Sistema Penal e politica criminal. Porto Alegre: Livraria do Advogado, 2010.

CANCIO MELIÁ, Manuel. Algunas reflexiones preliminares sobre los delitos de terrorismo: eficacia y contaminación. In DIAZMAROTO Y VILLAREJO, Julio. Derecho y justicia penal en siglo XXI: liber amicorum en homenaje al profesor Antonio GonzálezCuéllar García. Madrid: Editorial Colex, 2006. cap. 3, p. 487-495.

CANCIO MELIÁ, Manuel. Los delitos de terrorismo: estructura típica e injusto. Madrid: Editora Reus, 2010.

CAPITA REMEZAL, Mario. Análisis de la legislación penal antiterrorista. Madrid: Editorial Colex, 2008.
CEPEDA, Ana Isabel Pérez. La seguridad como fundamento de la deriva del Derecho penal postmoderno. Madrid: Iustel, 2007.

CORNELLI, Roberto. Miedo, criminalidad y orden. Tradução de Flavia Valgiusti, Joaquín Octavio Marcet e Carla Amans. Montevidéu: Editorial B de F, 2012.

DÍEZ RIPOLLÉS, José Luis. La política criminal en la encrucijada. Buenos Aires: B de F, 2007.

FERRAJOLI, Luigi. Principia iuris: teoria del diritto e della democrazia. 2. Teoria della democrazia. Itália, Bari: Ediroti Laterza, 2007, v. 2.

HASSEMER, Winfried. Derecho Penal simbólico y protección de bienes jurídicos. In: BUSTOS RAMIREZ, Juan (Dir.). Pena y Estado. Santiago: Editorial Jurídica ConoSur, 1995. p. 23-36.

HUSAK, Douglas. Sobrecriminalización: los límites del Derecho penal. Traducción e introducción de Rocío Lorda Ferreccio. Madrid: Marcial Pons, 2013.

JAKOBS, Günther; CANCIO MELIÁ, Manuel. Direito penal do inimigo: noções e críticas. Organização e tradução de André Luís Callegari e Nereu José Giacomolli. 6. ed. Porto Alegre: Livraria do Advogado, 2012.

JUANATEY DORADO, Carmen (Dir.); FERNÁNDEZ-PACHECO ESTRADA, Cristina. El nuevo panorama del terrorismo en España: perspectiva penal, penitenciaria y social. Alicante: Publicaciones de la Universidad de Alicante, 2013.

LLOBET ANGLÍ, Mariona. Derecho penal del terrorismo: límites de su punición en un Estado democrático. Madrid: La Ley, 2010 .

PÉREZ ROYO, Javier (Dir.); CARRASCO DURÁN, Manuel (coord.). Terrorismo, democracia y seguridad, en perspectiva constitucional. Marcial Pons: Madrid, 2010.

REVILLA MONTOYA, Pablo César. El terrorismo global. Inicio, desafios y médios político-jurídicos de enfrentamiento. Anuario Mexicano de Derecho Internacional. México, v. 5.

SENDEREY, Israel Drapkin. Imprensa e criminalidade. Tradução de Ester Kosovski. São Paulo: José Bushatsky Editor, 1983.

SILVA SÁNCHEZ, Jesús-María. A expansão do direito penal: aspectos da politica criminal nas sociedades pós-industriais. Tradução de Luiz Otavio de Oliveira Rocha. São Paulo: Editora Revista dos Tribunais, 2002

VIGANÒ, Francesco. Terrorismo, guerra e sistema penale. Rivista Italiana di Diritto e Procedura Penale, Milão, v. 49, p. 648-703, abr./jun. 2006.

WAINBERG, Jacques A. Mídia e terror: comunicação e violência política. São Paulo: Paulus, 2005.

WILKINSON, Paul. Terrorismo político. Rio de Janeiro: Artenova, 1976.

ZAFFARONI. Eugenio Raúl. O inimigo no direito penal. Rio de Janeiro: Revan. 2007.

\section{NOTAS}

1 Doutor honoris causa pela Universidade Autónoma de Tlaxcala México. Doutor honoris causa pelo Centro Universitário del Valle de Teotihuacan - México. Professor de Direito Penal nos Cursos de graduação e pós-graduação da Escola de Direito da Universidade do Vale do Rio dos Sinos - UNISINOS. Advogado Criminalista.

2 Bolsista FAPERGS de iniciação científica. Membro do grupo de pesquisa "Sistemas Punitivos", da UNISINOS, sob a coordenação do prof. Dr. André Luís Callegari. Integrante do Projeto de Pesquisa "Estado e Política Criminal: a expansão do Direito Penal como forma de combate ao terrorista". E-mail: <raullinhares@gmail.com>.

3 PÉREZ CEPEDA, Ana Isabel. La seguridad como fundamento de la deriva del Derecho penal postmoderno. Madrid: Editora Iustel, 2007. p. 309.

4 BAUMAN, Zygmunt. Medo líquido. Tradução de Carlos Alberto Medeiros. Rio de Janeiro: Zahar, 2008. p. 21.

5 BAUMAN, Zygmunt. Medo líquido. Tradução de Carlos Alberto Medeiros. Rio de Janeiro: Zahar, 2008. p. 14.

6 Para uma compreensão da Síndrome do Titanic: "Todos nós imaginamos que existe um iceberg esperando por nós, oculto em algum lugar no fundo nebuloso, com o qual nos chocaremos para afundar ouvindo música [...]." (ATTALI, Jacques, 1998 apud BAUMAN, Zygmunt. Medo líquido. Tradução de Carlos Alberto Medeiros. Rio de Janeiro: Zahar, 2008. p. 21). 
7 BAUMAN, Zygmunt. Medo líquido. Tradução de Carlos Alberto Medeiros. Rio de Janeiro: Zahar, 2008. p. 21.

8 DÍEZ RIPOLLÉS, José Luis. La política criminal en la encrucijada. Buenos Aires: B de F, 2007. p. 108. (tradução nossa).

9 ENDEREY, Israel Drapkin. Imprensa e criminalidade. Tradução de Ester Kosovski. São Paulo: José Bushatsky Editor, 1983. p. 39.

${ }^{10}$ CORNELLI, Roberto. Miedo, criminalidad y orden. Tradução de Flavia Valgiusti, Joaquín Octavio Marcet e Carla Amans. Montevidéu: Editorial B de F, 2012. p. 71.

11 WAINBERG, Jacques A. Mídia e terror: comunicação e violência política. São Paulo: Paulus, 2005. p. 31.

12 SENDEREY, Israel Drapkin. Imprensa e criminalidade. Tradução de Ester Kosovski. São Paulo: José Bushatsky Editor, 1983. p. 17-18.

13 RAMOS, João Gualberto Garcez. A inconstitucionalidade do "Direito Penal do Terror". Curitiba: Juruá, 1991. p. 12.

${ }^{14}$ CALlegARI, André Luis; WERMUTH, Maiquel Ângelo Dezordi. Sistema Penal e política criminal. Porto Alegre: Livraria do Advogado, 2010. p. 45.

15 JAKOBS, Günther; CANCIO MELIÁ, Manuel. Direito penal do inimigo: noções e críticas. Organização e tradução de André Luís Callegari e Nereu José Giacomolli. 6. ed. Porto Alegre: Livraria do Advogado, 2012. p. 79 .

16 JAKOBS, Günther; CANCIO MELIÁ, Manuel. Direito penal do inimigo: noções e críticas. Organização e tradução de André Luís Callegari e Nereu José Giacomolli. 6. ed. Porto Alegre: Livraria do Advogado, 2012. p. 88 .

17 DÍEZ RIPOLLÉS, José Luis. La política criminal en la encrucijada. Buenos Aires: B de F, 2007. p. 76. (tradução nossa).

${ }^{18}$ SILVA SÁNCHEZ, Jesús-María. A expansão do direito penal: aspectos da política criminal nas sociedades pós-industriais. Tradução de Luiz Otavio de Oliveira Rocha. São Paulo: Editora Revista dos Tribunais, 2002. p. 23

19 BAUMAN, Zygmunt. Medo líquido. Tradução de Carlos Alberto Medeiros. Rio de Janeiro: Zahar, 2008. p. 149.

${ }^{20}$ HUSAK, Douglas. Sobrecriminalización: los límites del Derecho penal. Traducción e introducción de Rocío Lorda Ferreccio. Madrid: Marcial Pons, 2013. p. 57

${ }^{21}$ DÍEZ RIPOLLÉS, José Luis. La política criminal en la encrucijada. Buenos Aires: B de F, 2007. p. 79. (tradução nossa).

22 BECCARIA, Cesare. Dos delitos e das penas. Tradução Neury Carvalho Lima. São Paulo: Hunter Books, 2012. p. 20.

${ }^{23}$ HUSAK, Douglas. Sobrecriminalización: los límites del Derecho penal. Traducción e introducción de Rocío Lorda Ferreccio. Madrid: Marcial Pons, 2013. p. 52.

${ }^{24}$ CALLEGARI, André Luís. Teoria geral do delito e da imputação objetiva. 3. ed. São Paulo: Atlas, 2014. p. 3.

${ }^{25}$ CEPEDA, Ana Isabel Pérez. La seguridad como fundamento de la deriva del Derecho penal postmoderno. Madrid: Iustel, 2007. p. 313.

26 JAKOBS, Günther; CANCIO MELIÁ, Manuel. Direito penal do inimigo: noções e críticas. Organização e tradução de André Luís Callegari e Nereu José Giacomolli. 6. ed. Porto Alegre: Livraria do Advogado, 2012. p. 34.

${ }^{27}$ BACIGALUPO, Enrique. Derecho penal y el Estado de Derecho. Chile: Editorial Juridica de Chile, 2005. p. 85.

28 JAKOBS, Günther; CANCIO MELIÁ, Manuel. Direito penal do inimigo: noções e críticas. Organização e tradução de André Luís Callegari e Nereu José Giacomolli. 6. ed. Porto Alegre: Livraria do Advogado, 2012. p. 26.

29 ZAFFARONI. Eugenio Raúl. O inimigo no direito penal. Rio de Janeiro: Revan. 2007. p. 18.

${ }^{30}$ VIGANÒ, Francesco. Terrorismo, guerra e sistema penale. Rivista Italiana di Diritto e Procedura Penale, Milão, v. 49, p. 670, abr./jun. 2006.

31 JAKOBS, Günther; CANCIO MELIÁ, Manuel. Direito penal do inimigo: noções e críticas. Organização e tradução de André Luís Callegari e Nereu José Giacomolli. 6. ed. Porto Alegre: Livraria do Advogado, 2012. p. 94.

32 JAKOBS, Günther; CANCIO MELIÁ, Manuel. Direito penal do inimigo: noções e críticas. Organização e tradução de André Luís Callegari e Nereu José Giacomolli. 6. ed. Porto Alegre: Livraria do Advogado, 2012. p. 74

33 ARLACCHI, Pino. Il mito del terrorismo. Revista de Estudos Criminais, São Paulo, ano 10, n. 45, p. 11, abr./jun.2012.
${ }^{34}$ CAPITA REMEZAL, Mario. Análisis de la legislación penal antiterrorista. Madrid: Editorial Colex, 2008.

${ }^{35}$ CANCIO MELIÁ, Manuel. Los delitos de terrorismo: estructura típica e injusto. Madrid: Editora Reus, 2010.

36 CANCIO MELIÁ, Manuel. Los delitos de terrorismo: estructura típica e injusto. Madrid: Editora Reus, 2010. p. 82.

37 ARROYO ZAPATERO, L., 1985 apud CAPITA REMEZAL, Mario. Análisis de la legislación penal antiterrorista. Madrid: Editorial Colex, 2008. p. 25 .

${ }^{38}$ REVILLA MONTOYA, Pablo César. El terrorismo global. Inicio, desafios y médios político-jurídicos de enfrentamiento. Anuario Mexicano de Derecho Internacional. México, v. 5, p. 406, 2005.

${ }^{39}$ BECERRA RAMÍREZ, Manuel. El 11 de septiembre y el derecho internacional. In: VALDÉS UGALDE, José Luis; VALADÉS, Diego (Org.). Globalidad y conflicto: Estados Unidos y la crisis de septiembre. México: Instituto de Investigaciones Jurídicas, 2002. p. 259.

${ }^{40}$ WILKINSON, Paul. Terrorismo político. Rio de Janeiro: Editora Artenova, 1976. p. 13.

${ }^{41}$ BAUMAN, Zygmunt. Medo líquido. Tradução de Carlos Alberto Medeiros. Rio de Janeiro: Zahar, 2008. p. 140.

${ }^{42}$ WAINBERG, Jacques A. Mídia e terror: comunicação e violência política. São Paulo: Paulus, 2005. p. 15.

${ }^{3}$ WAINBERG, Jacques A. Mídia e terror: comunicação e violência política. São Paulo: Paulus, 2005. p. 63.

44 VIGANÒ, Francesco. Terrorismo, guerra e sistema penale. Rivista Italiana di Diritto e Procedura Penale, Milão, v. 49, p. 655, abr./jun. 2006.

${ }^{45}$ CANCIO MELIÁ, Manuel. Los delitos de terrorismo: estructura típica e injusto. Madrid: Editora Reus, 2010. p. 57.

${ }^{46}$ CANCIO MELIÁ, Manuel. Los delitos de terrorismo: estructura típica e injusto. Madrid: Editora Reus, 2010. p. 56

${ }^{47}$ HUSAK, Douglas. Sobrecriminalización: los límites del Derecho penal. Traducción e introducción de Rocío Lorda Ferreccio. Madrid: Marcial Pons, 2013. p. 57.

48 CANCIO MELIÁ, Manuel. Los delitos de terrorismo: estructura típica e injusto. Madrid: Editora Reus, 2010. p. 73.

${ }^{49}$ FERRAJOLI, Luigi. Principia iuris: teoria del diritto e della democrazia 2. Teoria della democrazia. Itália, Bari: Ediroti Laterza, 2007, v. 2. p. 364

${ }^{50}$ Nesse mesmo sentido, refere Manuel Cancio Meliá: "Parece que en el caso de estos grupos, es especialmente claro que resulta imposible desarticular - usando sólo medios de persecución criminal y duraderamente - una organización multicéntrica y carente de una verdadera estructura funcional en su conjunto." (CANCIO MELIÁ, Manuel. Los delitos de terrorismo: estructura típica e injusto. Madrid: Editora Reus, 2010. p. 61)

51 FERRAJOLI, Luigi. Principia iuris: teoria del diritto e della democrazia. 2. Teoria della democrazia. Itália, Bari: Ediroti Laterza, 2007, v. 2. p. 507.

52 CANCIO MELIÁ, Manuel. Los delitos de terrorismo: estructura típica e injusto. Madrid: Editora Reus, 2010. p. 77.

53 CANCIO MELIÁ, Manuel. Algunas reflexiones preliminares sobre los delitos de terrorismo: eficacia y contaminación. In DIAZ-MAROTO Y VILLAREJO, Julio. Derecho y justicia penal en siglo XXI: liber amicorum en homenaje al profesor Antonio González-Cuéllar García. Madrid: Editorial Colex, 2006. cap. 3, p. 491.

${ }^{54}$ LLOBET ANGLÍ, Mariona. Derecho penal del terrorismo: límites de su punición en un Estado democrático. Madrid: La Ley, 2010. p. 140-141 e 145 .

55 CANCIO MELIÁ, Manuel. Algunas reflexiones preliminares sobre los delitos de terrorismo: eficacia y contaminación. In DIAZ-MAROTO Y VILLAREJO, Julio. Derecho y justicia penal en siglo XXI: liber amicorum en homenaje al profesor Antonio González-Cuéllar García. Madrid: Editorial Colex, 2006. cap. 3, p. 488.

${ }^{56}$ FERRAJOLI, Luigi. Principia iuris: teoria del diritto e della democrazia. 2. Teoria della democrazia. Itália, Bari: Ediroti Laterza, 2007, v. 2. p. 508-509.

57 BAUMAN, Zygmunt. Medo líquido. Tradução de Carlos Alberto Medeiros. Rio de Janeiro: Zahar, 2008. p. 159.

${ }^{58}$ PÉREZ CEPEDA, Ana Isabel. La seguridad como fundamento de la deriva del Derecho penal postmoderno. Madrid: Editora Iustel, 2007. p. 173.

59 VIGANÒ, Francesco. Terrorismo, guerra e sistema penale. Rivista Italiana di Diritto e Procedura Penale, Milão, v. 49, p. 653, abr./jun. 2006. 